\title{
The Requirement for Acetate of a Streptomycin-resistant Strain of Staphylococcus aureus
}

\author{
BY JOAN F. GARDNER* AND JUNE LASCELLES \\ Microbiology Unit, Department of Biochemistry, University of Oxford
}

(Received 18 December 1961)

\begin{abstract}
SUMMARY
A streptomycin-resistant strain of Staphylococcus aureus, which requires haemin for aerobic growth, grew either aerobically or anaerobically in the absence of haemin provided the medium was supplemented with acetate or pyruvate; growth with these organic acids was increased by uracil and purines. The parent drug-sensitive strain grew aerobically without haemin but when grown anaerobically required either uracil or acetate or pyruvate. With both strains mevalonate replaced acetate and was about ten times more active.

The products of glucose fermentation by both strains showed no gross difference, lactate being predominant (about $85 \%$ of the glucose carbon); only small amounts of acetate were detected. Under aerobic conditions suspensions of the parent strain oxidized glucose to acetate which accumulated. The mutant strain oxidized glucose to acetate only when previously grown with haemin or when haemin was added to the suspension of organisms. When the organism was grown with acetate in place of haemin, lactate was the predominant product. The ability of the mutant to form sufficient acetate from glucose for biosynthetic purposes is apparently dependent on a functional electron transport chain involving haemoproteins. A nicotinamide-adenine dinucleotide-linked lactate dehydrogenase and a pyruvate oxidizing system are present in extracts of both organisms. The activity of these enzymes in the mutant strain was similar whether the organisms were grown on haemin or acetate.
\end{abstract}

\section{INTRODUCTION}

Jensen \& Thofern (1953) described a streptomycin-resistant strain of Staphylococcus aureus (Var 511) which, unlike the parent sensitive strain, required haemin for growth. Later work showed that the mutant grew without haemin in a medium containing acetate or pyruvate; purines and uracil increased growth under these conditions (Lascelles, 1956). The mutant did not form haem compounds when grown on acetate in place of haemin since organisms grown in this way neither respired nor reduced nitrate; these activities were present only in organisms grown on haemin (Jensen \& Thofern, 1953; Lascelles, 1956). In the present work the requirement of the mutant and parent strains for acetate has been examined more thoroughly. In addition, analyses have been made of the end products of glucose metabolism by suspensions of the parent and mutant strains to see whether these provided evidence for differing pathways of glucose breakdown which might account for the requirement of the mutant for preformed acetate when grown without haemin.

* Present address : Department of Bacteriology, University of Melbourne, Australia. 


\section{METHODS}

Organisms. The two strains of Staphylococcus aureus used were obtained from Dr J. Jensen. The parent organism (SG 511A) was streptomycin-sensitive and grew without added haemin while the mutant strain (SG511 Var) was streptomycinresistant and required haemin (Jensen \& Thofern, 1953). Stock cultures were maintained on chocolate blood agar as previously described (Lascelles, 1956).

Medium. The basal medium used throughout contained per 1.: Difco casamino acids (vitamin-free) $3 \mathrm{~g} . ;$ L-cysteine hydrochloride, $100 \mathrm{mg}$; DL- tryptophan, 50 mg.; $\mathrm{Na}_{2} \mathrm{HPO}_{4} .12 \mathrm{H}_{2} \mathrm{O}, 7$ g.; $\mathrm{K}_{2} \mathrm{HPO}_{4}, 5.5$ g.; $\mathrm{KH}_{2} \mathrm{PO}_{4}, 500 \mathrm{mg}$.; $\mathrm{NaCl}, 2 \mathrm{~g}$; $\mathrm{MgSO}_{4} \cdot 7 \mathrm{H}_{2} \mathrm{O}$, $100 \mathrm{mg}$; ferric citrate, $1 \mathrm{mg}$.; nicotinic acid, $1 \mathrm{mg}$; thiamine

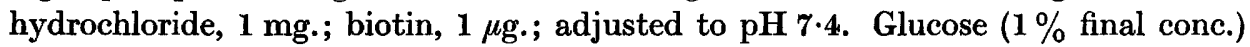
was added after autoclaving. Supplements to this medium are indicated in the text.

Growth tests. Aerobic cultures were in $18 \mathrm{~mm}$. tubes containing $5 \mathrm{ml}$. medium incubated in air without shaking. Anaerobic cultures were grown in completely filled glass-stoppered bottles containing $32 \mathrm{ml}$. medium. The inoculum was prepared by suspending organisms from a chocolate blood agar slope in water to a concentration equivalent to about $\mathbf{0 . 4} \mathbf{m g}$. dry wt./ml.; dilutions of this suspension were added to the medium to give an initial concentration density equiv. about $0.001 \mathrm{mg}$. dry wt. $/ \mathrm{ml}$. Incubation was at $37^{\circ}$. Amounts of growth and concentrations of suspensions were measured with an EEL colorimeter (Evans Electroselenium Ltd., Halstead, Essex), an instrument reading of 10 being equivalent to $0.42 \mathrm{mg}$. dry wt./ml.

Preparation of suspensions. Cultures were grown in $250 \mathrm{ml}$. flasks containing $125 \mathrm{ml}$. medium inoculated with organisms from the chocolate blood agar slopes to give an initial concentration equiv. about $0.01 \mathrm{mg}$. dry wt./ml. Incubation was in air (without shaking) for $16 \mathrm{hr}$. at $37^{\circ}$. Organisms were harvested by centrifugation and washed in one half the original culture volume of $0.02 \mathrm{M}$-potassium phosphate


$(\mathrm{pH} 7 \cdot 4)$ to a concentration equiv. 2-4 $\mathrm{mg}$. dry wt./ml.

Manometry. Conventional Warburg techniques were used. Details of the vessel contents and atmosphere are given in the text. Incubation was at $37^{\circ}$.

Analytical methods. After incubation, suspensions were removed from the manometer cups, the organisms removed by centrifugation and samples of the supernatant fluid analysed for lactate and acetate. Lactate was determined by the method of Barker \& Summerson (1941) and acetate as described by Rose (1955). Protein was estimated by the method of Lowry, Rosebrough, Farr \& Randall (1951), with crystalline bovine serum albumin (Armour Laboratories Ltd., Hampden Park, Eastbourne, Sussex) as standard.

Assays of enzymic activity. Cell-free extracts were made by shaking $10 \mathrm{ml}$. suspension (equiv. $10 \mathrm{mg}$. dry wt. $/ \mathrm{ml}$. in 0.04 M-potassium phosphate buffer, $\mathrm{pH} \mathrm{7.4)} \mathrm{with} 10 \mathrm{~g}$. ballotini (grade 12) beads for $5 \mathrm{~min}$. in a Mickle disintegrator (Mickle, 1948). After centrifugation at $20,000 \mathrm{~g}$, for $10 \mathrm{~min}$. at $0^{\circ}$, the clear supernatant fluid was assayed for lactate dehydrogenase and pyruvate oxidizing activity. Lactate dehydrogenase was measured by following the rate of oxidation of reduced nicotinamide-adenine dinucleotide $\left(\mathrm{NADH}_{2}\right)$ in the presence of pyruvate at 
$340 \mathrm{~m} \mu$. Each cuvette $(1 \mathrm{~cm}$. light path) contained in a final volume of $3 \mathrm{ml}$.: potassium phosphate buffer $\mathrm{pH} 7 \cdot 0,300 \mu$ moles; sodium pyruvate, $20 \mu$ moles; extract, 0.05-0.2 mg. protein; $\mathrm{NADH}_{2} \mathbf{0 . 3} \mu$ mole (except in the blank). The reaction was started by addition of pyruvate. Units of activity are expressed as $\mu$ moles of $\mathrm{NADH}_{2}$ oxidized/min. Pyruvate oxidizing activity was measured by observing the rate of reduction of $2: 6$-dichlorophenol-indophenol in the presence of pyruvate at $600 \mathrm{~m} \mu$. Each cuvette $(1 \mathrm{~cm}$. light path) contained in a final volume of $3 \mathrm{ml}$.: potassium phosphate buffer ( $\mathrm{pH} \mathrm{7.0)}$ ), $300 \mu$ moles; $\mathrm{MgCl}_{2}, 10 \mu$ moles; thiamine pyrophosphate, 0.1 $\mu$ mole; 2:6-dichlorophenol-indophenol, $0 \cdot 2 \mu$ mole; extract 0.5-2 mg. protein; sodium pyruvate, $40 \mu$ moles (except in the blank). The reaction was started by addition of the substrate. Units of activity are expressed as $\mu$ moles of dye reduced $/ \mathrm{min}$. The spectrophotometric assays were carried out with an Optica recording spectrophotometer, Model CF4DR (Optica Ltd., Gateshead, Co. Durham).

Special chemicals. Stock solutions of haemin (1 mM) were dissolved in $0 \cdot 02 \mathrm{~N}-\mathrm{NaOH}$ in $50 \%(\mathrm{v} / \mathrm{v})$ ethanol. It was added to media after autoclaving. Sodium DLmevalonate was prepared by neutralizing the lactone (British Drug Houses, Ltd., Poole, Dorset). Details of other materials were as previously described (Lascelles, 1956, 1960).

\title{
RESULTS
}

\section{Growth of parent and mutant strains}

Aerobiosis and anaerobiosis. The parent strain grew aerobically on the unsupplemented basal medium containing glucose, amino acids and B-group vitamins; but anaerobically the addition of purines and uracil or of acetate or pyruvate was

Table 1. Requirements for aerobic and anaerobic growth of parent and mutant strains of Staphylococcus aureus

\begin{abstract}
Cultures were grown for $27 \mathrm{hr}$. in the basal medium supplemented where shown with: PU (a mixture of adenine, xanthine and uracil, $0.1 \mathrm{~mm}$ each); sodium acetate or pyruvate, $10 \mathrm{~mm}$. ; or haemin, $0.001 \mathrm{~mm}$. Details of the procedures for aerobic and anaerobic incubation are given in Methods. Growth is expressed as optical density readings on the EEL colorimeter.
\end{abstract}

$\begin{gathered}\text { Additions to } \\ \text { basal medium }\end{gathered}$
Nil
PU
Acetate
PU + acetate
Pyruvate
PU + pyruvate
Haemin

\begin{tabular}{|c|c|c|c|}
\hline \multicolumn{4}{|c|}{ Growth } \\
\hline \multicolumn{2}{|c|}{ Parent strain } & \multicolumn{2}{|c|}{ Mutant strain } \\
\hline Aerobic & Anaerobic & Aerobic & Anaerobic \\
\hline 22 & 1.5 & 1.5 & $\mathbf{0}$ \\
\hline 21 & 19 & 0 & $\mathbf{0}$ \\
\hline 20 & 14 & 25 & 17 \\
\hline 21 & 18 & 32 & 22 \\
\hline 21 & 19 & $\mathbf{3 1}$ & 22 \\
\hline 21 & 19 & 30 & 27 \\
\hline 17 & $\mathbf{0}$ & 21 & $\mathbf{0}$ \\
\hline
\end{tabular}

necessary (Table 1). Of the nucleic acid derivatives tested, uracil was essential as found previously for Staphylococcus (Richardson, 1936); the purines merely improved anaerobic growth. Anaerobic growth of the parent strain with acetate was increased by the addition of nucleic acid derivatives. 
Haemin promoted growth of the mutant strain only under aerobic conditions (Table 1). The oxygen tension necessary to support full growth under these conditions could not have been high since static cultures in $18 \mathrm{~mm}$. diameter tubes containing $10 \mathrm{ml}$. medium grew just as well as those in vigorously shaken flasks. Growth of the mutant in the absence of haemin occurred either aerobically or anaerobically when the basal medium was supplemented with acetate or pyruvate (Table 1). The further addition of a mixture of adenine, xanthine and uracil improved the yield but, unlike the parent organism, nucleic acid derivatives alone did not support anaerobic growth.

Replacement of acetate by mevalonic acid. The requirement of some lactobacilli for acetate is replaced by mevalonic acid, a key intermediate in the biosynthesis of isoprenoid derivatives such as sterols (Skeggs et al. 1956; Popjak \& Cornforth, 1960). This compound also replaced acetate for growth of the mutant strain of Staphylococcus used here (Table 2). Mevalonate was 10 times more active than acetate though the lag period was longer than in cultures growing with acetate. Addition of mevalonate to the basal medium also promoted anaerobic growth of the parent strain.

Table 2. Activity of mevalonate for growth of the mutant strain Staphylococcus aureus ( $S G 511$ Var)

The basal medium was supplemented with adenine, xanthine and uracil
each). Cultures were incubated aerobically as described in Methods and growth
as EEL colorimeter readings.
$\begin{aligned} & \text { Additions to medium } \\ & \text { (mM.) }\end{aligned}$
Nil
Sodium acetate $\left\{\begin{array}{lrc}1 & 28 \mathrm{hr} \text { Growth } & 52 \mathrm{hr} \text {. } \\ 3 & 0 & 0.5 \\ \text { Sodium mevalonate } \begin{cases}0.1 \\ 0.3\end{cases} & 1 & 3 \\ \text { Haemin } 0.001 & 2 & 14 \\ \end{array}\right.$

Anaerobic metabolism of glucose by suspensions of organisms

The obligatory requirement of the mutant for acetate (or pyruvate) for growth without haemin, whereas the parent strain grew anaerobically without added acetate in the presence of nucleic acid derivatives, suggested that the end products of glucose fermentation by the two strains might differ. No evidence for any major difference was, however, found. Lactic acid was the main end-product formed by incubation of suspensions of both parent and mutant organisms anaerobically in phosphate buffer (Table 3, Expt. 1). Small amounts of $\mathrm{CO}_{2}$ were also formed but only trace amounts of volatile acids were detected after steam distillation of the fermentation mixtures. Acetoin was not detectable by the test of Barritt (1936). Suspensions of the mutant harvested from cultures containing either haemin or acetate and nucleic acid derivatives behaved similarly (Table 3). Suspensions of both parent and mutant organisms fermented pyruvate to lactic and acetic acids and $\mathrm{CO}_{2}$ in equimolar amounts, as found previously with other strains of Staphylococcus aureus (Krebs, 1937). The mutant strain behaved similarly whether grown with haemin or acetate. 
The fermentation of glucose was also studied with organisms suspended in the basal medium instead of phosphate buffer. In these experiments acetate was estimated by the sensitive enzymic method of Rose (1955). With both parent and mutant organisms, irrespective of the medium from which they were harvested, lactate was again the major end-product, amounting to about $1.5 \mu \mathrm{mole} / \mu \mathrm{mole}$ glucose (Table 3, Expt. 2). The amounts of acetate formed by suspensions of both organisms were of the same order, $0 \cdot 1-0 \cdot 15 \mu$ mole $/ \mu$ mole glucose. The amount of acetate formed by the parent strain or by the mutant grown with haemin was however always more than that formed by the mutant grown without haemin; but the analyses did not provide any obvious clue to account for the ability of the parent to grow anaerobically in the absence of added acetate.

\section{Table 3. Fermentation of glucose by suspensions of parent and mutant strains of Staphylococcus aureus}

The organisms were grown on the basal medium supplemented as shown with 10 mM. sodium acetate and $0.1 \mathrm{~mm}$. each of adenine, xanthine and uracil (Ac-PU) or with 0.001 mu. haemin (H). In Expt. 1, each double side-armed manometer cup contained: organisms (equiv. $2.5 \mathrm{mg}$. dry wt. $/ \mathrm{ml}$.) $1.0 \mathrm{ml}$; potassium phosphate buffer $(\mathrm{pH} \mathrm{7.4)}$ $250 \mu$ moles; glucose (when present) $10 \mu$ moles added from one side arm at zero time; $\mathrm{H}_{2} \mathrm{O}$ to $2.5 \mathrm{ml}$.

In Expt. 2, double-strength basal medium (1.25 ml.) was present in place of the phosphate buffer.

Incubation was at $37^{\circ}$ in $\mathrm{N}_{2}$ for $1 \mathrm{hr}$. in Expt. 1 , for $3 \mathrm{hr}$. in Expt. 2. To estimate $\mathrm{CO}_{2}$, $0 \cdot 1 \mathrm{ml} .4 \mathrm{~N}-\mathrm{H}_{2} \mathrm{SO}_{4}$ was added from the other side arm at the end of the reaction to liberate bound $\mathrm{CO}_{2}$. Lactate and acetate were estimated with suspensions incubated in the same way, except that $\mathrm{H}_{2} \mathrm{SO}_{4}$ was not added at the end of the reaction.

\begin{tabular}{|c|c|c|c|c|c|c|c|}
\hline \multirow[b]{2}{*}{ Expt. } & \multirow[b]{2}{*}{ Strain } & \multirow{2}{*}{$\begin{array}{l}\text { Growth } \\
\text { medium }\end{array}$} & \multirow{2}{*}{$\begin{array}{c}\text { Glucose } \\
\text { (10 } \mu \text { moles) }\end{array}$} & \multicolumn{3}{|c|}{ Product ( $\mu$ moles) } & \multirow{2}{*}{$\begin{array}{c}\text { Glucose } \mathbf{C} \\
\text { recovered } \\
(\%) \dagger\end{array}$} \\
\hline & & & & $\mathrm{CO}_{2}$ & Lactate & Acetate* & \\
\hline 1 & Parent & Ac-PU & $\overline{+}$ & $\begin{array}{l}1 \cdot 7 \\
3 \cdot 2\end{array}$ & $\begin{array}{c}0 \\
17.0\end{array}$ & - & 93 \\
\hline & Mutant & $\begin{array}{l}\text { Ac-PU } \\
\text { H }\end{array}$ & $\frac{-}{+}$ & $\begin{array}{l}0 \cdot 7 \\
2 \cdot 7 \\
1 \cdot 7 \\
3 \cdot 4\end{array}$ & $\begin{array}{c}0 \\
16 \cdot 6 \\
0 \\
17 \cdot 0\end{array}$ & 二 & 94 \\
\hline 2 & Parent & $\begin{array}{l}\text { Ac-PU } \\
\text { Basal }\end{array}$ & $\begin{array}{l}- \\
+ \\
+\end{array}$ & $\begin{array}{l}0 \cdot 6 \\
3 \cdot 3 \\
0 \cdot 6 \\
2 \cdot 9\end{array}$ & $\begin{array}{r}0.2 \\
13 \cdot 8 \\
0 \cdot 2 \\
14.8\end{array}$ & $\begin{array}{l}0 \cdot 6 \\
2 \cdot 1 \\
0 \cdot 7 \\
1 \cdot 6\end{array}$ & $\begin{array}{l}89 \\
89\end{array}$ \\
\hline & Mutant & $\begin{array}{l}\text { Ac-PU } \\
\mathbf{H}\end{array}$ & $\frac{-}{+}$ & $\begin{array}{l}0 \cdot 4 \\
5 \cdot 4 \\
0 \cdot 4 \\
5 \cdot 6\end{array}$ & $\begin{array}{r}0.2 \\
15.7 \\
0.2 \\
18.9\end{array}$ & $\begin{array}{l}0.5 \\
0.6 \\
0.7 \\
1.6\end{array}$ & 100 \\
\hline
\end{tabular}

* Acetate was not estimated in Expt. 1.

$\dagger$ Glucose (C) accounted for after subtraction of endogenous values.

\section{Aerobic metabolism of glucose by suspensions of organisms}

The oxidation of glucose was examined with suspensions of the parent and mutant strains incubated aerobically in the basal growth medium (Table 4). Acetate was the major end-product $(1 \cdot 3 \mu \mathrm{mole} / \mu$ mole glucose) formed by the parent organism when harvested from the basal medium with or without acetate. The mutant strain 
formed a similar amount of acetate only when previously grown on haemin, or when haemin was added to the manometer cups. Mutant organisms harvested from the acetate + nucleic acid medium formed only small amounts of acetate, lactate being the major end product; such suspensions showed only slight oxygen consumption. The ability of the mutant strain to grow without acetate aerobically in the presence of haemin. was therefore correlated with its ability to oxidize glucose to acetate under these conditions.

Table 4. Aerobic metabolism of glucose by suspensions of the parent and mutant strains of Staphylococcus aureus

Organisms were grown on the basal medium supplemented with acetate, purines and uracil or with haemin (see Table 3). Each manometer vessel contained: organisms (equiv. 2.5 mg. dry wt./ml.), $1.0 \mathrm{ml}$. double-strength basal medium, $1.25 \mathrm{ml}$; glucose (when present) $10 \mu$ moles, added from the side arm at zero time; $\mathrm{H}_{2} \mathrm{O}$ to $2.5 \mathrm{ml}$. The centre wells contained $0.2 \mathrm{ml} .20 \% \mathrm{NaOH}$. Incubation was at $37^{\circ}$ in air for $3 \mathrm{hr}$.

\begin{tabular}{|c|c|c|c|c|c|}
\hline \multirow[b]{2}{*}{ Strain } & \multirow[b]{2}{*}{$\begin{array}{l}\text { Growth } \\
\text { medium }\end{array}$} & \multirow[b]{2}{*}{$\begin{array}{c}\text { Glucose } \\
10 \mu \text { moles) }\end{array}$} & \multirow[b]{2}{*}{$\underset{(\mu \text { moles })}{\mathbf{O}_{2} \text { uptake }}$} & \multicolumn{2}{|c|}{ Products ( $\mu$ moles) } \\
\hline & & & & Acetate & Lactate \\
\hline Parent & $\begin{array}{l}\text { Ac-PU } \\
\text { Basal }\end{array}$ & $\begin{array}{l}- \\
+ \\
+\end{array}$ & $\begin{array}{r}2 \cdot 5 \\
52 \cdot 5 \\
5 \\
62\end{array}$ & $\begin{array}{c}1 \cdot 0 \\
12 \cdot 5 \\
1 \cdot 65 \\
12 \cdot 75\end{array}$ & $\begin{array}{l}0 \cdot 1 \\
0 \cdot 5 \\
0 \cdot 1 \\
0 \cdot 3\end{array}$ \\
\hline Mutant & $\begin{array}{l}\text { Ac-PU } \\
\text { H }\end{array}$ & $\begin{array}{l}- \\
+ \\
+\end{array}$ & $\begin{array}{c}1 \cdot 5 \\
2 \cdot 6 \\
7 \cdot 5 \\
56\end{array}$ & $\begin{array}{c}0 \cdot 6 \\
1 \cdot 2 \\
1 \cdot 35 \\
14 \cdot 25\end{array}$ & $\begin{array}{r}0.1 \\
16 \cdot 0 \\
0 \cdot 1 \\
0.2\end{array}$ \\
\hline
\end{tabular}

Table 5. Lactic dehydrogenase and pyruvate oxidase activities in extracts of parent and mutant strains of Staphylococcus aureus Extracts were prepared as described in Methods from organisms grown in the basal
medium supplemented as described in Table 3. The enzyme activities were assayed as
described in Methods and are expressed as units/mg. protein. At least 3 different extracts
from each group were assayed and the values shown are the mean with the range in brackets.

\begin{tabular}{clcl} 
Strain & $\begin{array}{c}\text { Growth } \\
\text { medium }\end{array}$ & $\begin{array}{c}\text { Lactate } \\
\text { dehydrogenase }\end{array}$ & \multicolumn{1}{c}{$\begin{array}{c}\text { Pyruvate } \\
\text { oxidase }\end{array}$} \\
Parent & Basal & $6 \cdot 4(5 \cdot 2-7 \cdot 7)$ & $0 \cdot 11(0 \cdot 07-0 \cdot 13)$ \\
& Ac-PU & $6 \cdot 0(5 \cdot 0-6 \cdot 5)$ & Not determined \\
Mutant & H & $5 \cdot 6(4 \cdot 4-6 \cdot 8)$ & $0 \cdot 17 *$ \\
& Ac-PU & $5 \cdot 6(5 \cdot 0-6 \cdot 0)$ & $0 \cdot 11(0 \cdot 08-0 \cdot 14)$ \\
& \multicolumn{2}{r}{ * One estimation only. }
\end{tabular}

\section{Enzymic activity of cell-free extracts}

The requirement of the mutant strain for acetate might have been due to an active lactate dehydrogenase coupled with a low pyruvate oxidizing system. In such a situation pyruvate formed from glucose would be rapidly reduced to lactate and might not be available for acetate formation via pyruvate oxidase. However, no evidence for this was found by assay of these enzymes in cell-free extracts (Table 5). Extracts of the mutant and parent strains had a highly active NADlinked lactate dehydrogenase (specific for the $\mathrm{L}(+)$ )isomer) and both types of 
extract exhibited a pyruvate oxidase system. There was no significant difference in the level of these enzymes in the parent and mutant strains nor did the presence of haemin or of acetate in the growth medium influence the enzymic activity found in the extracts.

\section{DISCUSSION}

Nutritional studies have provided abundant evidence that acetate is an essential metabolite for micro-organisms. It is required by some lactobacilli in media lacking lipoic acid which is part of the pyruvate oxidase complex (Reed, 1957). Other lactobacilli require either acetate or mevalonate (Wagner \& Folkers, 1961). In these organisms the main function of acetate appears to be as a precursor of mevalonate, a key intermediate in the biosynthesis of isoprenoid derivatives (Popjak \& Cornforth, 1960). The precise structure of the bacterial isoprenoids is unknown but they are probably present in the non-saponifiable fraction of the lipids. The activity of mevalonate in replacing acetate for growth of the strains of Staphylococcus studied in this work suggests that the major function of acetate in these organisms is also for the formation of mevalonate.



Fig. 1. Scheme for glucose metabolism in Staphylococcus.

Growth experiments with the mutant strain of Staphylococcus suggest that it can form sufficient acetate for its biosynthetic needs only when an electron transport chain involving haemoproteins is functioning; either oxygen or nitrate can act as ultimate hydrogen acceptor under these circumstances (Lascelles, 1956). This interpretation of the growth experiments was confirmed by analysis of the end products of glucose metabolism. Acetate is the major end-product formed by haemin-grown organisms incubated aerobically but with those grown without haemin, lactate is the predominant end-product under both aerobic and anaerobic conditions.

The ability of the parent strain to grow anaerobically without added acetate provided uracil and purines are present suggests that it can make sufficient acetate by anaerobic mechanisms to satisfy its requirements for biosynthetic reactions while the mutant cannot. Evidence for a gross difference in fermentation pathways in the two organisms was not shown by the analyses; but the amount of acetate accumulated by the parent, although slight, was consistently higher than that formed by the mutant. 
Since lactate is the main end-product of glucose fermentation by both strains reduction of pyruvate by a NAD-linked lactate dehydrogenase is apparently the main outlet for substrate hydrogen (see Fig. 1). For conversion of pyruvate, derived from glucose, to acetate an additional hydrogen acceptor system is required ( $X$ in Fig. 1 ) and this may be lacking in the mutant strain. Under aerobic conditions, provided there is a complete electron transport chain including haemoproteins, the problem of an outlet for substrate hydrogen is solved by the use of molecular oxygen.

The ability of added pyruvate to replace acetate for anaerobic growth of these staphylococci is readily explained by the pyruvate dismutation system which converts pyruvate to acetate, lactate and $\mathrm{CO}_{2}$ (Krebs, 1937). Pyruvate was previously shown to be needed for anaerobic growth of other strains of Staphylococcus (Richardson, 1936). The present experiments throw no light on the question of why the parent strain requires for growth either nucleic acid derivatives or acetate. The whole problem of the requirement of Staphylococcus for nucleic acid derivatives for anaerobic growth remains unsolved.

We are grateful to Professor D. D. Woods, F.R.S., for his interest and encouragement. One of us (J.F.G.) held an Overseas Research Fellowship of Lady Margaret Hall, Oxford during this work. The research was supported by a grant to the Department from the Rockefeller Foundation and from the United States Public Health Service.

\section{REFERENCES}

Barritt, M. M. (1936). The intensification of the Voges-Proskauer reaction by the addition of $\alpha$-naphthol. J. Path. Bact. 42, 441.

Barker, S. B. \& Summerson, W. H. (1941). The colorimetric determination of lactic acid in biological material. J. biol. Chem. 138, 535.

Jensen, J. \& Thofern, E. (1953). Chlorohämin (Ferri porphyrinchloride) als Bakterienwuchsstoff. I. Z. Naturf. $8 b, 599$.

KREBS, H. A. (1937). Dismutation of pyruvic acid in gonococcus and staphylococcus. Biochem. J. 31, 661.

LASCELlES, J. (1956). An assay of iron protoporphyrin based on the reduction of nitrate by a variant strain of Staphylococcus aureus; synthesis of iron protoporphyrin by suspensions of Rhodopseudomonas spheroides. J. gen. Microbiol. 15, 404.

LASCELLES, J. (1960). The synthesis of enzymes concerned in bacteriochlorophyll formation in growing cultures of Rhodopseudomonas spheroides. J. gen. Microbiol. 23, 487.

Lowry, O. H., Rosebrough, N. J., Farr, A. L. \& Randall, R. J. (1951). Protein measurement with the Folin phenol reagent. J. biol. Chem. 193, 265.

Mickle, H. (1948). Tissue disintegrator. J. Roy. Micr. Soc. 68 (Series III), 10.

PopJak, G. \& Connfonth, J. W. (1960). The biosynthesis of cholesterol. Advanc. Enzymol. 22, 281.

REED, L. J. (1957). The chemistry and function of lipoic acid. Advanc. Enzymol. 18, 319.

Richardson, G. M. (1936). The nutrition of Staphylococcus aureus. Necessity for uracil in anaerobic growth. Biochem. $J .30,2184$.

Rose, I. A. (1955). In Methods in Enzymology, 1, 591. Ed. S. P. Colowick and N. O. Kaplan. New York: Academic Press Inc.

Skeggs, H. R., Wright, L. D., Cresson, E. L., Macrae, G. D. E., Hoffman, C. H., Wolf, D. E. \& Folkers, K. (1956). Discovery of a new acetate replacing factor. J. Bact. 72, 519.

WAGNer, A. F. \& Folkers, K. (1961). Discovery and chemistry of mevalonic acid. Advanc. Enzymol. 23, 471. 